\title{
Erratum to: The European Modern Pollen Database (EMPD) project
}

Basil A. S. Davis • Marco Zanon • Pamella Collins • Achille Mauri •

Johan Bakker • Doris Barboni - Alexandra Barthelmes · Celia Beaudouin ·

H. John B. Birks • Anne E. Bjune - Elissaveta Bozilova - Richard H. W. Bradshaw •

Barbara A. Brayshay $\cdot$ Simon Brewer $\cdot$ Elisabetta Brugiapaglia $\cdot$ Jane Bunting ·

Simon E. Connor · Jacques-Louis de Beaulieu • Kevin J. Edwards •

Ana Ejarque · Patricia Fall - Assunta Florenzano - Ralph Fyfe • Didier Galop •

Marco Giardini · Thomas Giesecke • Michael J. Grant • Jöel Guiot •

Susanne Jahns • Vlasta Jankovská • Stephen Juggins • Marina Kahrmann •

Monika Karpińska-Kołaczek • Piotr Kołaczek · Norbert Kühl • Petr Kuneš •

Elena G. Lapteva • Suzanne A. G. Leroy • Michelle Leydet · José Antonio López Sáez •

Alessia Masi - Isabelle Matthias • Florence Mazier • Vivika Meltsov •

Anna Maria Mercuri • Yannick Miras • Fraser J. G. Mitchell • Jesse L. Morris •

Filipa Naughton • Anne Birgitte Nielsen · Elena Novenko • Bent Odgaard •

Elena Ortu • Mette Venås Overballe-Petersen $\cdot$ Heather S. Pardoe •

Silvia M. Peglar · Irena A. Pidek • Laura Sadori · Heikki Seppä •

Elena Severova $\cdot$ Helen Shaw $\cdot$ Joanna Święta-Musznicka $\cdot$ Martin Theuerkauf •

Spassimir Tonkov $\cdot$ Siim Veski $\cdot$ Pim (W. O.) van der Knaap · Jacqueline F. N. van Leeuwen •

Jessie Woodbridge $\cdot$ Marcelina Zimny $\cdot$ Jed O. Kaplan

Published online: 20 June 2013

(C) Springer-Verlag Berlin Heidelberg 2013

\section{Erratum to: Veget Hist Archaeobot DOI 10.1007/s00334-012-0388-5}

Unfortunately, the list of authors contains a number of duplications, omissions and other errors in the original publication of the article. The correct list appears in this erratum.
The complete list of author addresses and e-mails is contained in the electronic supplementary material, to which should be added: H. John B. Birks, Department of Biology and Bjerknes Centre for Climate Research, University of Bergen, Post Box 7803, N-5020 Bergen, Norway, e-mail: john.birks@bio.uib.no.

The online version of the original article can be found under doi: $10.1007 / \mathrm{s} 00334-012-0388-5$.

B. A. S. Davis ( $\square)$

ARVE Group, School of Architecture Civil \& Environmental

Engineering, Station 2, Ecole Polytechnique Fédérale de

Lausanne, 1015 Lausanne, Switzerland

e-mail: basil.davis@epfl.ch 